\title{
Systematic screening and deep analysis of CoPt binding peptides leads to enhanced CoPt nanoparticles using designed peptides.
}

R. M. Jarrald, ${ }^{a}$ Aw Wei Liang Alvin, ${ }^{b}$ A. E. Rawlings, ${ }^{a}$ M. Tanaka, ${ }^{b}$ M. Okochi ${ }^{b}$ and S. S. Staniland ${ }^{a}$

a The University of Sheffield, Department of Chemistry, Dainton Building, Sheffield, S3 7HF

Email: s.s.staniland@sheffield.ac.uk

${ }^{\mathrm{b}}$ Department of Chemical Science and Engineering, Tokyo Institute of Technology, 2-12-1, O-okayama, Meguro-ku, Tokyo, 152-8522, Japan

Email: okochi.m.aa@m.titech.ac.jp

\section{Supplementary Information}

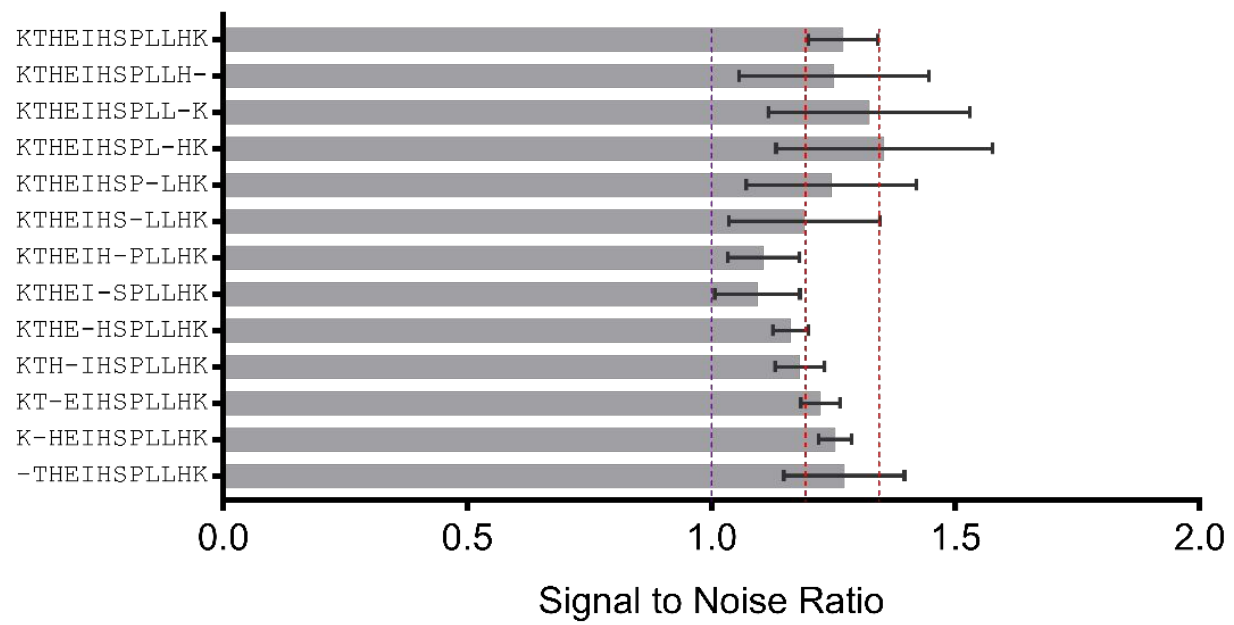

Figure S 1 - Alanine scanning data for LS1, screened against CoPt NPs. Dotted purple line represents background noise.

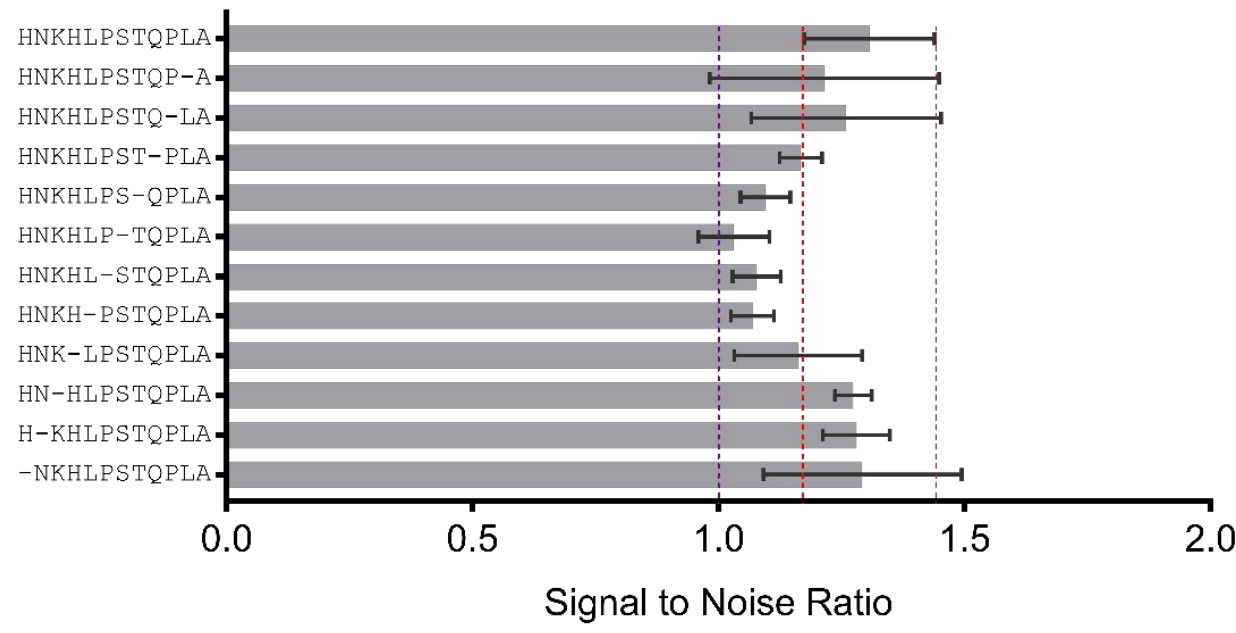

Figure S 2 - Alanine scanning data for LS2, screened against CoPt NPs. Dotted purple line represents background noise. 


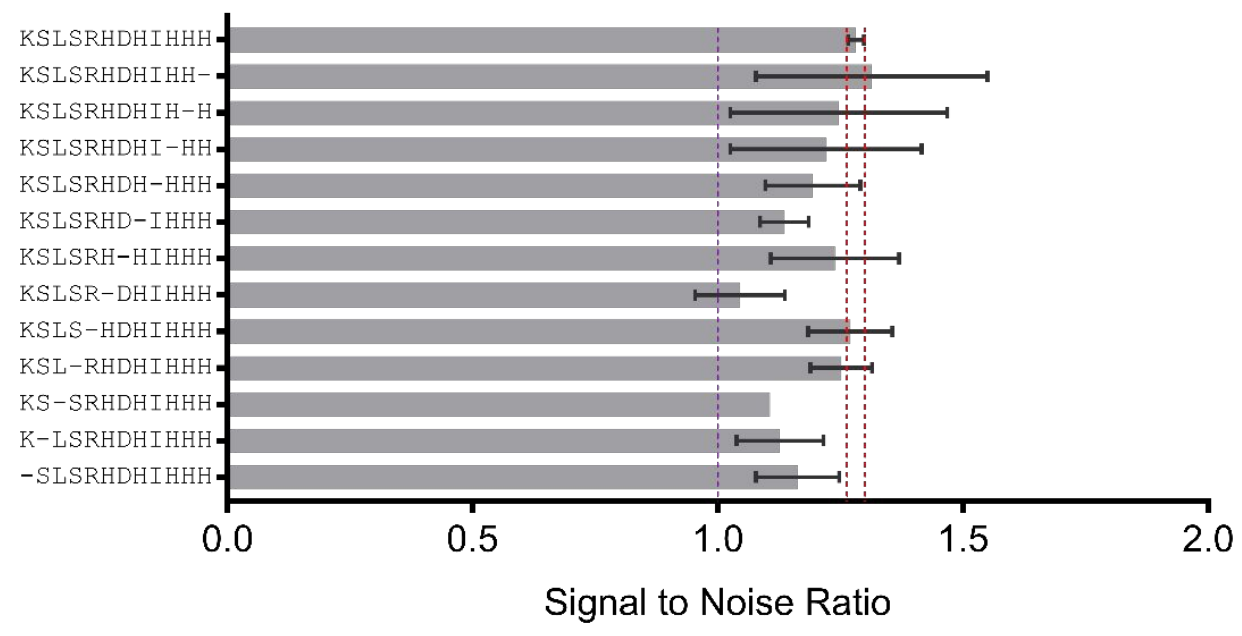

Figure S 3 - Alanine scanning data for LS3, screened against CoPt NPs. Dotted purple line represents background noise.

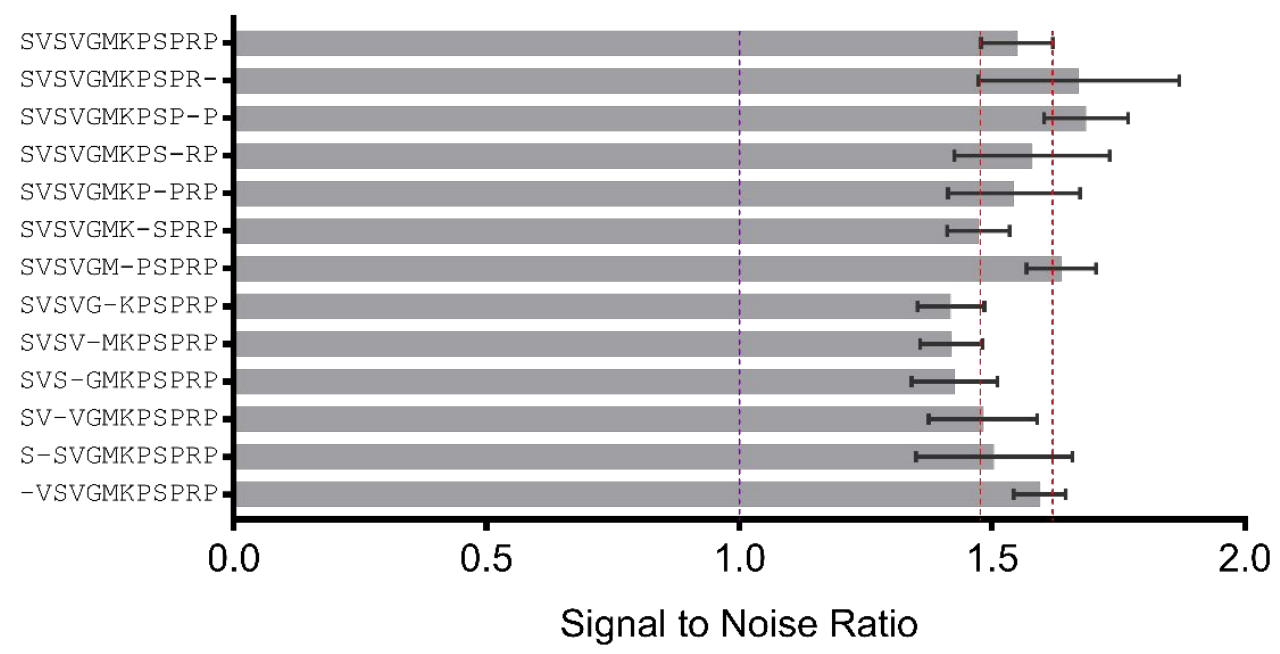

Figure S 4 - Alanine scanning data for LS4, screened against CoPt NPs. Dotted purple line represents background noise.

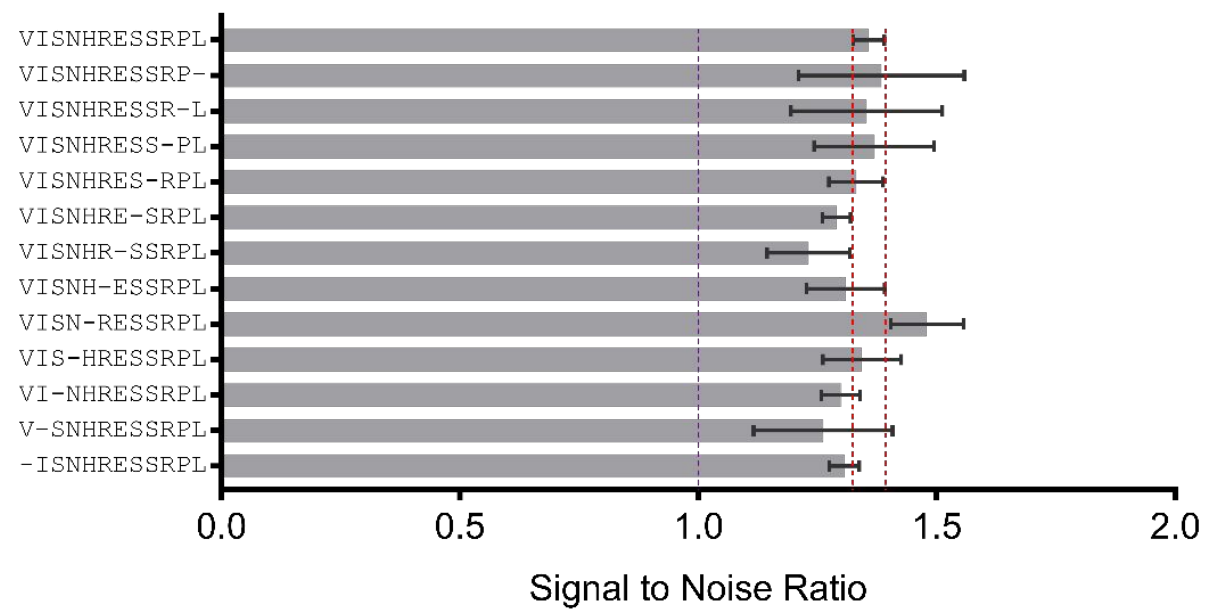

Figure S 5 - Alanine scanning data for LS5, screened against CoPt NPs. Dotted purple line represents background noise. 


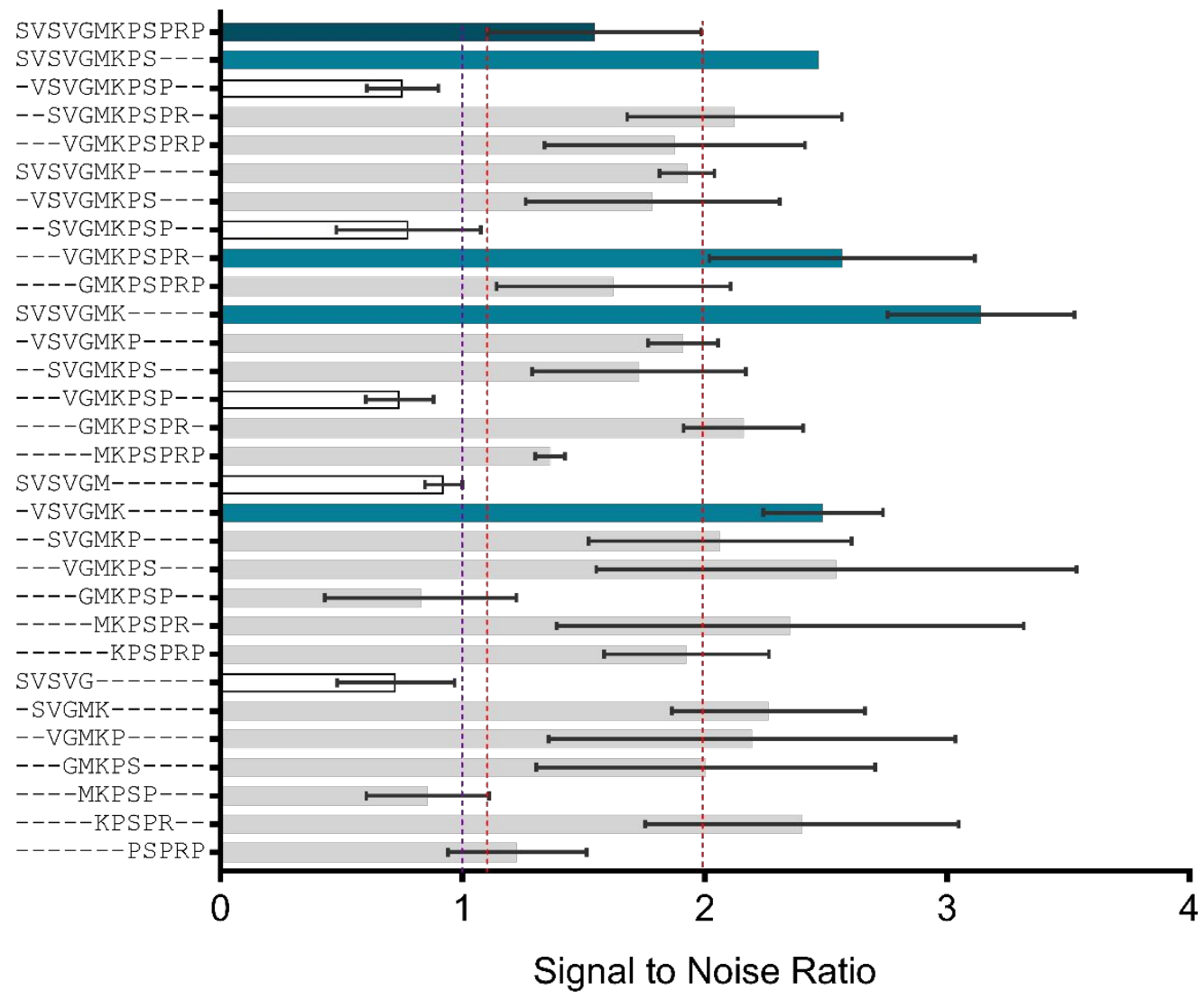

Figure S 6 - Truncation data for LS4, screened against CoPt NPs. Dark green - LS4, teal - increased SNR, grey - similar SNR and white - decreased SNR. Dotted purple line is background noise. 


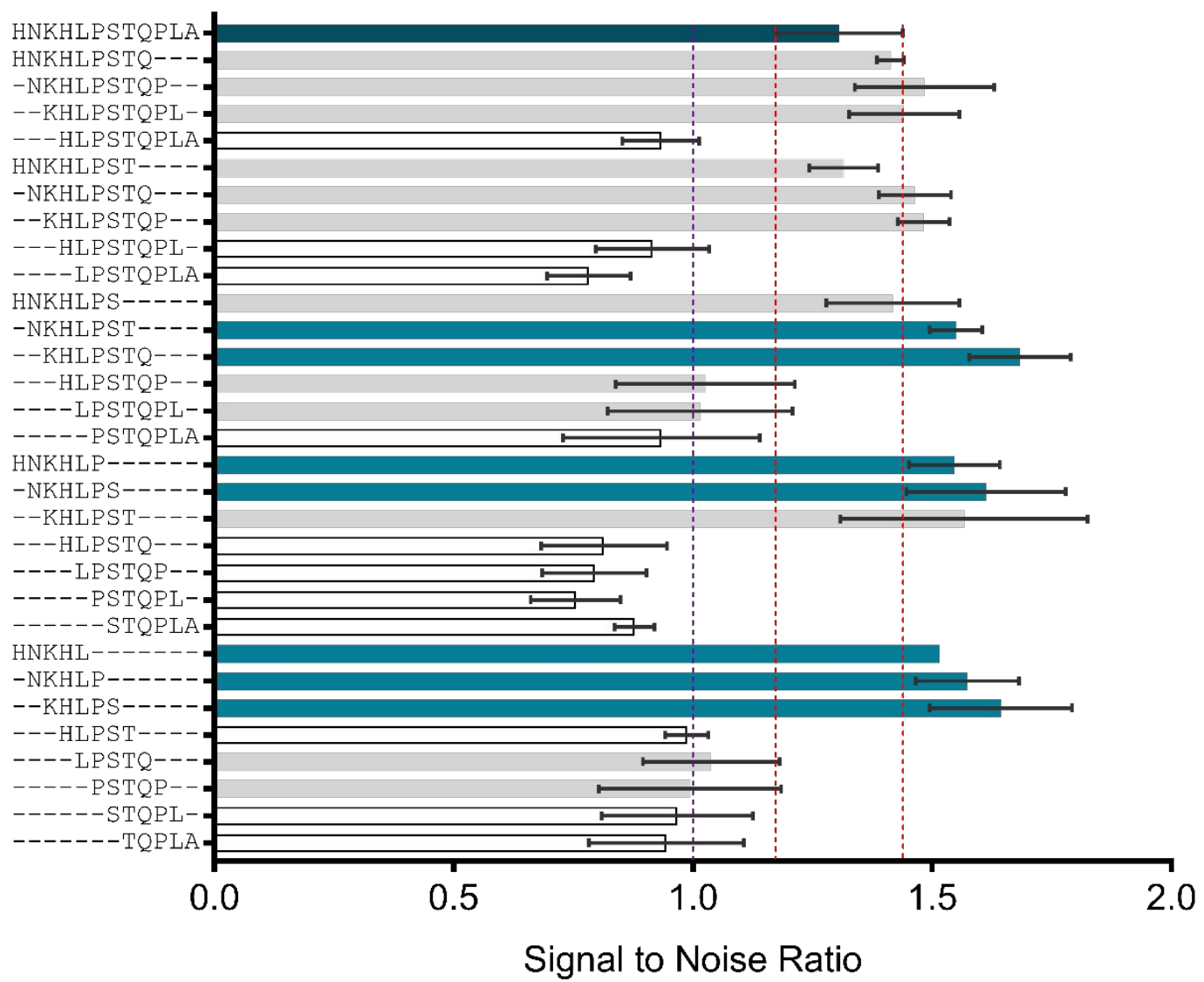

Figure S 7 - Truncation data for LS2, screened against CoPt NPs. Dark green - LS2, grey - similar SNR to LS2 and white - reduced SNR values. Dotted purple line represents background noise. 


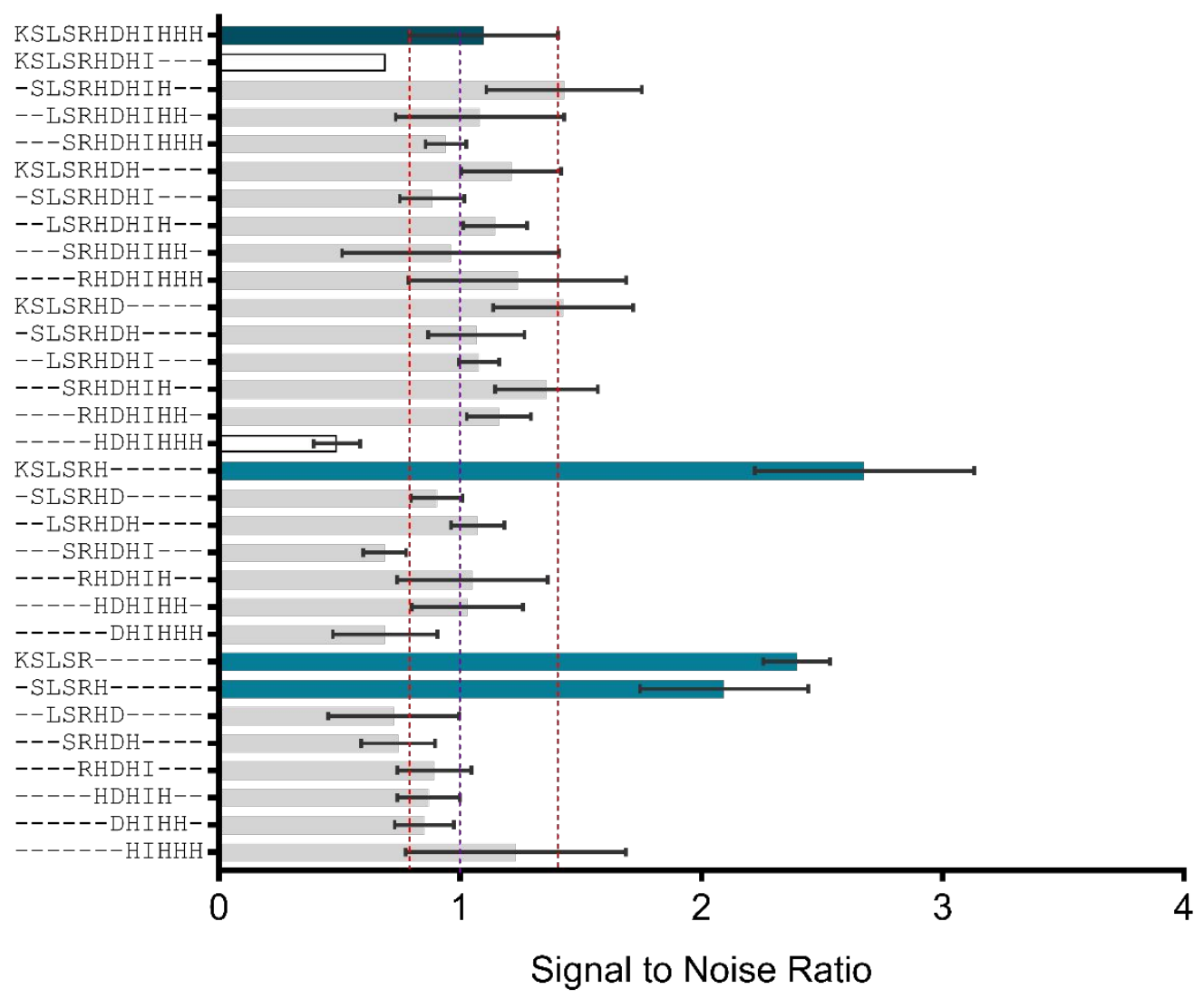

Figure S 8 - Truncation data for LS3, screened against CoPt NPs. Dark green - LS3, teal - increased SNR values, grey - similar SNR values and white - decreased SNR values. Dotted purple line represents background noise. 


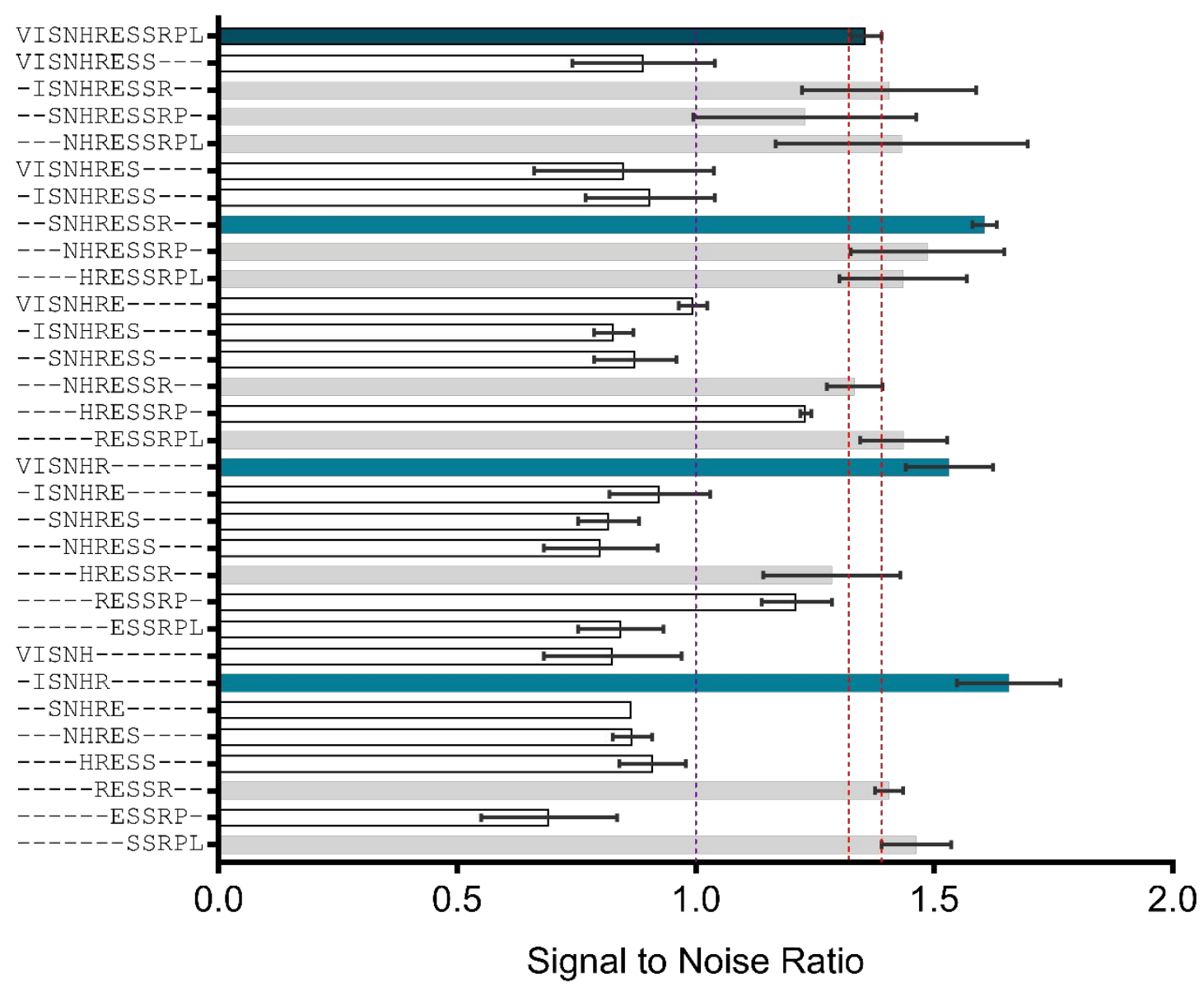

Figure S 9 - Truncation data for LS5, screened against CoPt NPs. Dark green - LS5, teal - increased SNR, grey - similar SNR and white - decreased SNR. Dotted purple line represents background noise.

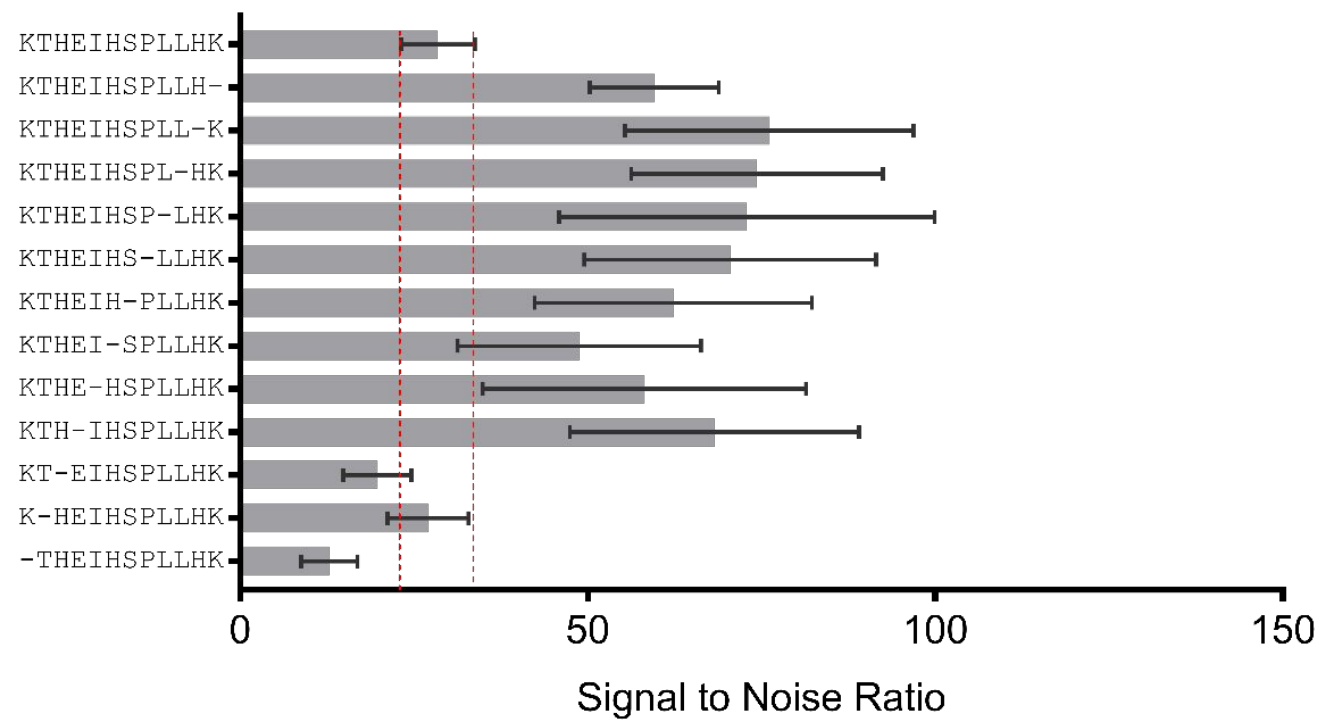

Figure S 10 - Alanine scanning data for LS1, screened against $\mathbf{P t}^{2+}$. 


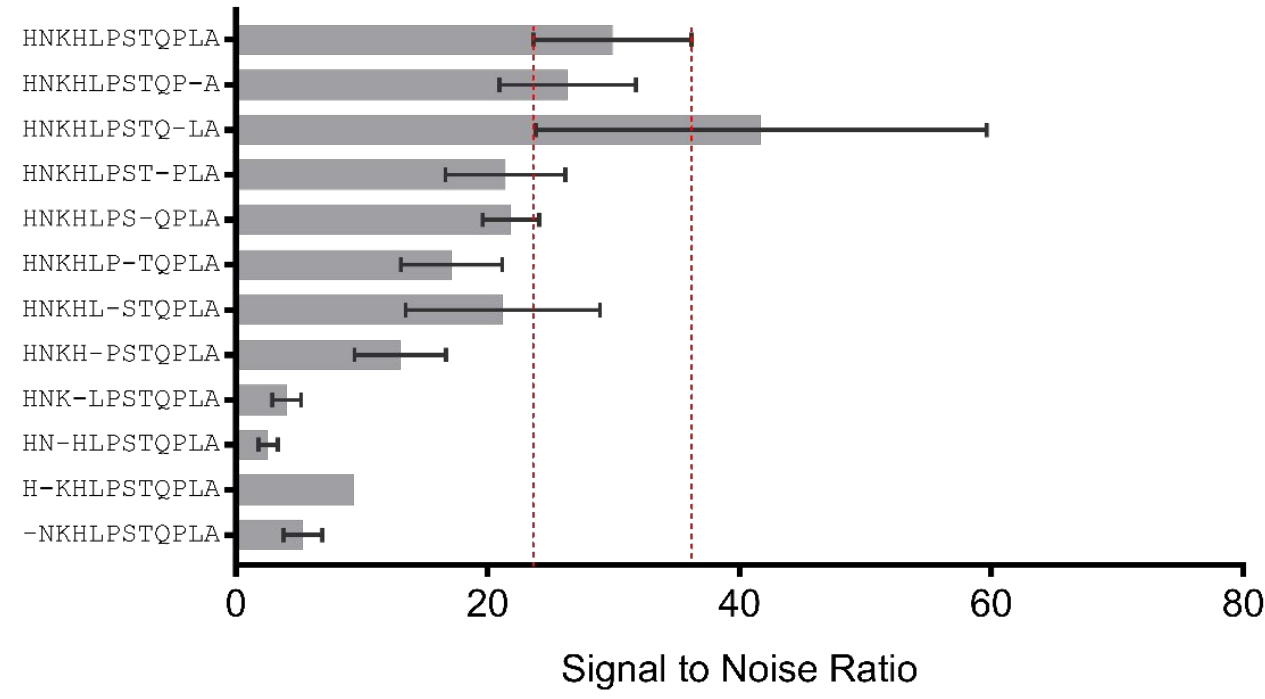

Figure S 11 - Alanine scanning data for LS2, screened against $\mathbf{P t}^{2+}$.

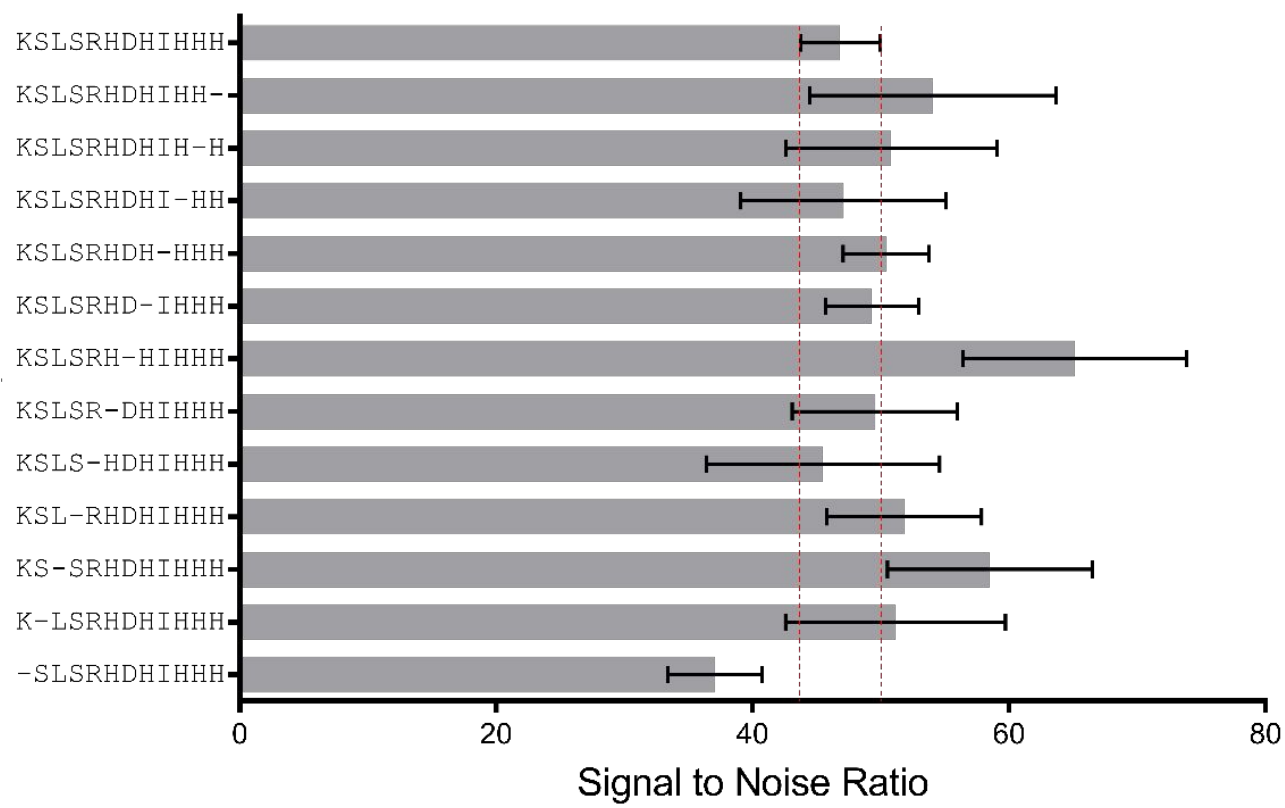

Figure S 12 - Alanine scanning data for LS3, screened against $\mathrm{Pt}^{2+}$. 


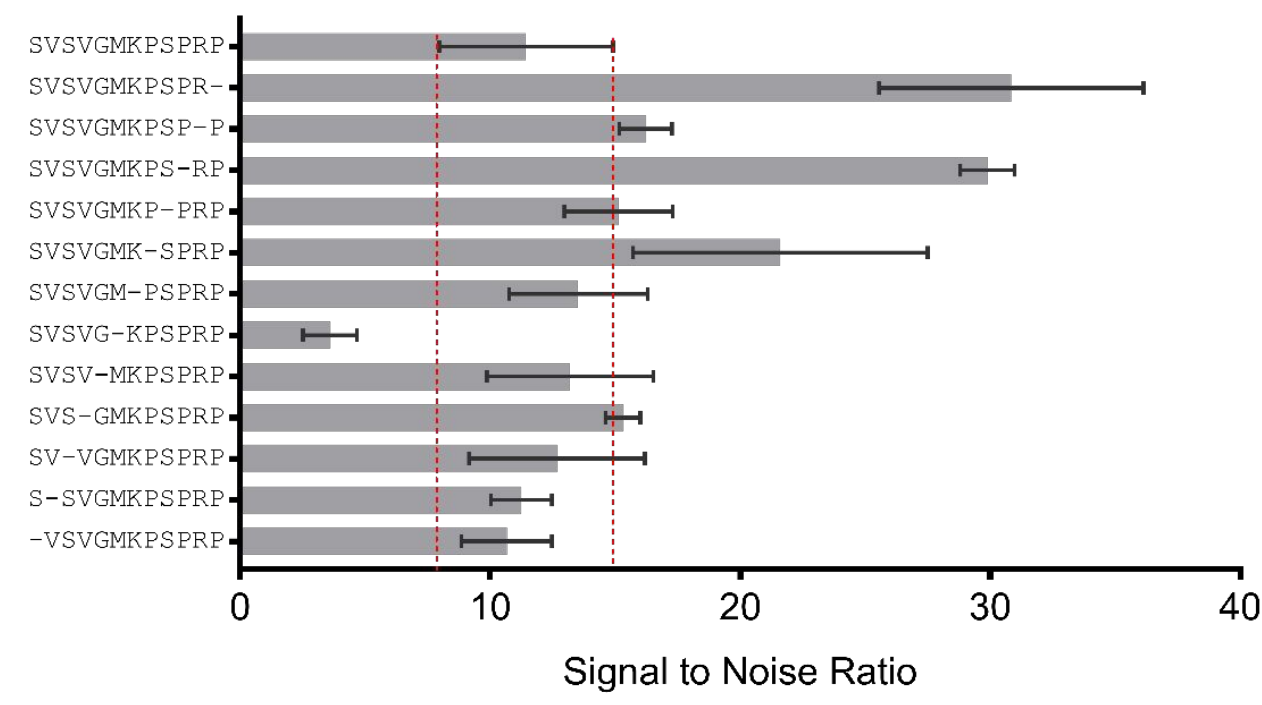

Figure S 13 - Alanine scanning data for LS4, screened against $\mathrm{Pt}^{2+}$.

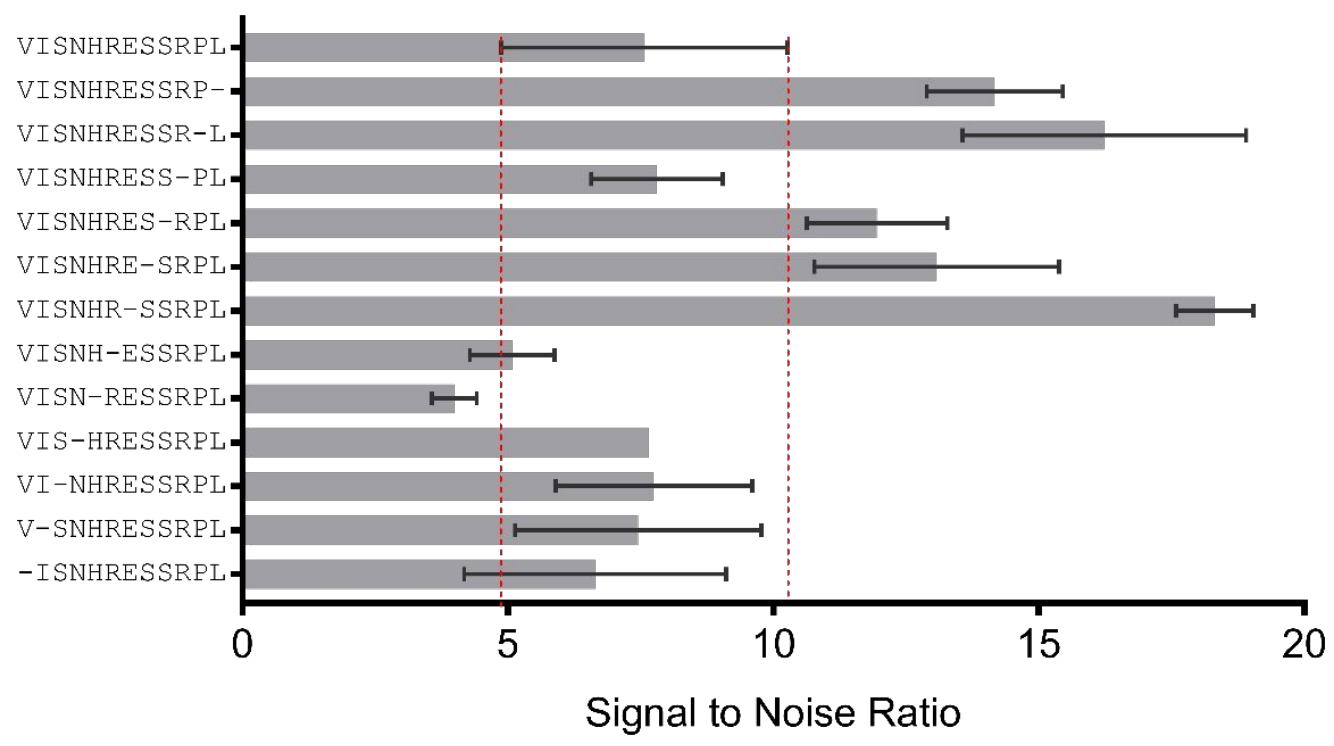

Figure S 14 - Alanine scanning data for LS5, screened against $\mathrm{Pt}^{2+}$. 


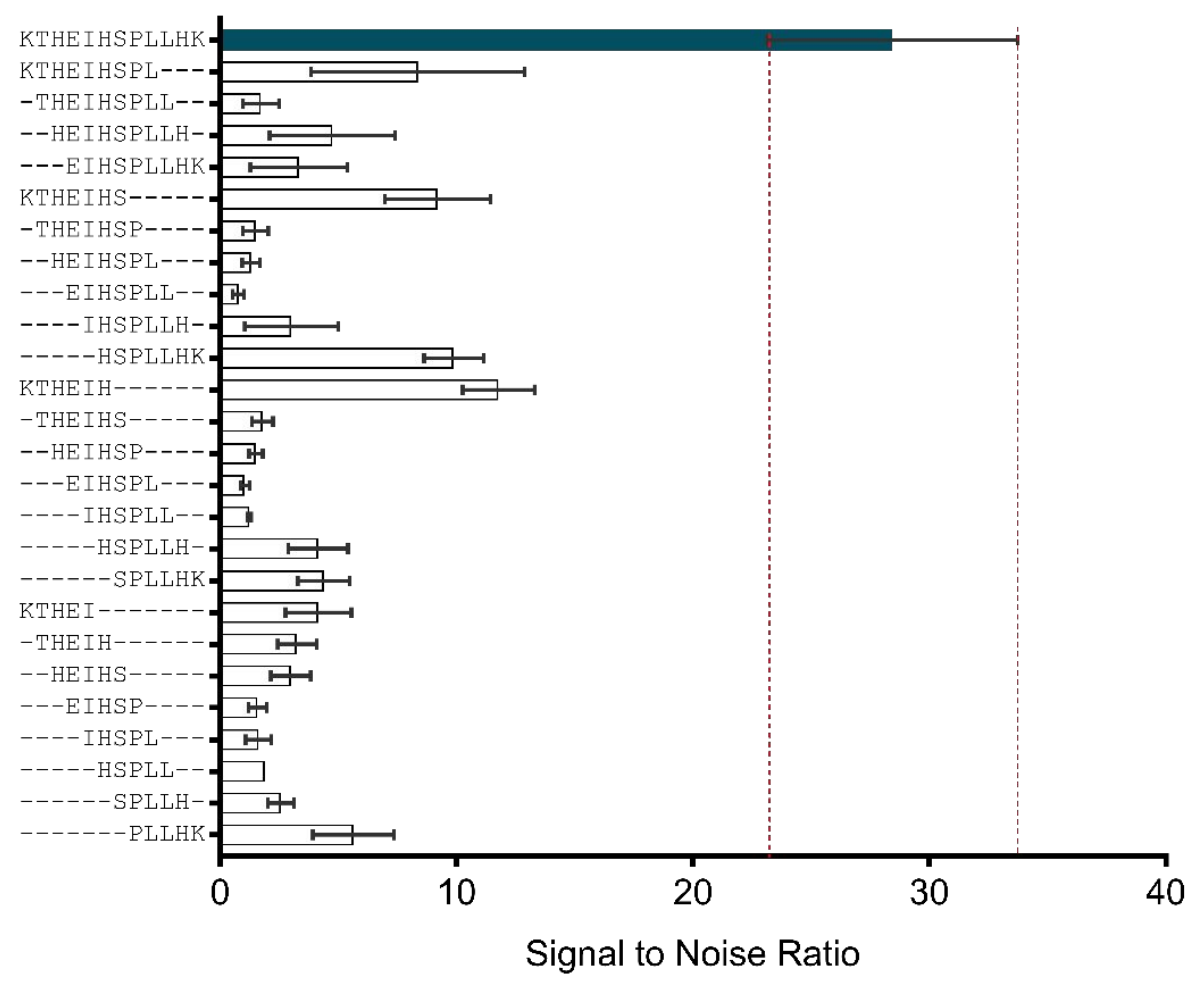

Figure S 15 - Truncation data for LS1, screened against $\mathrm{Pt}^{2+}$.

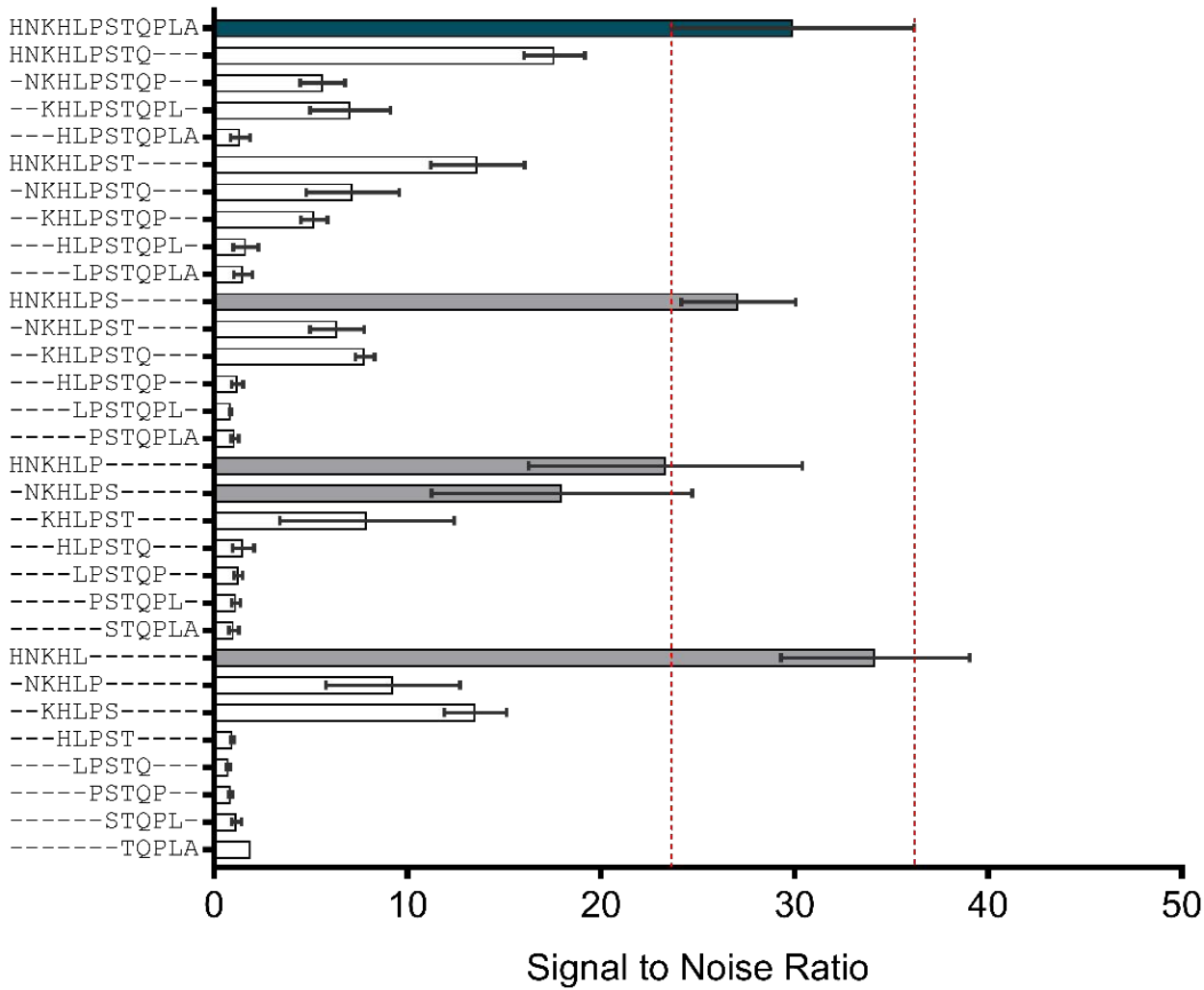

Figure S 16 - Truncation data for LS2, screened against $\mathrm{Pt}^{2+}$. 


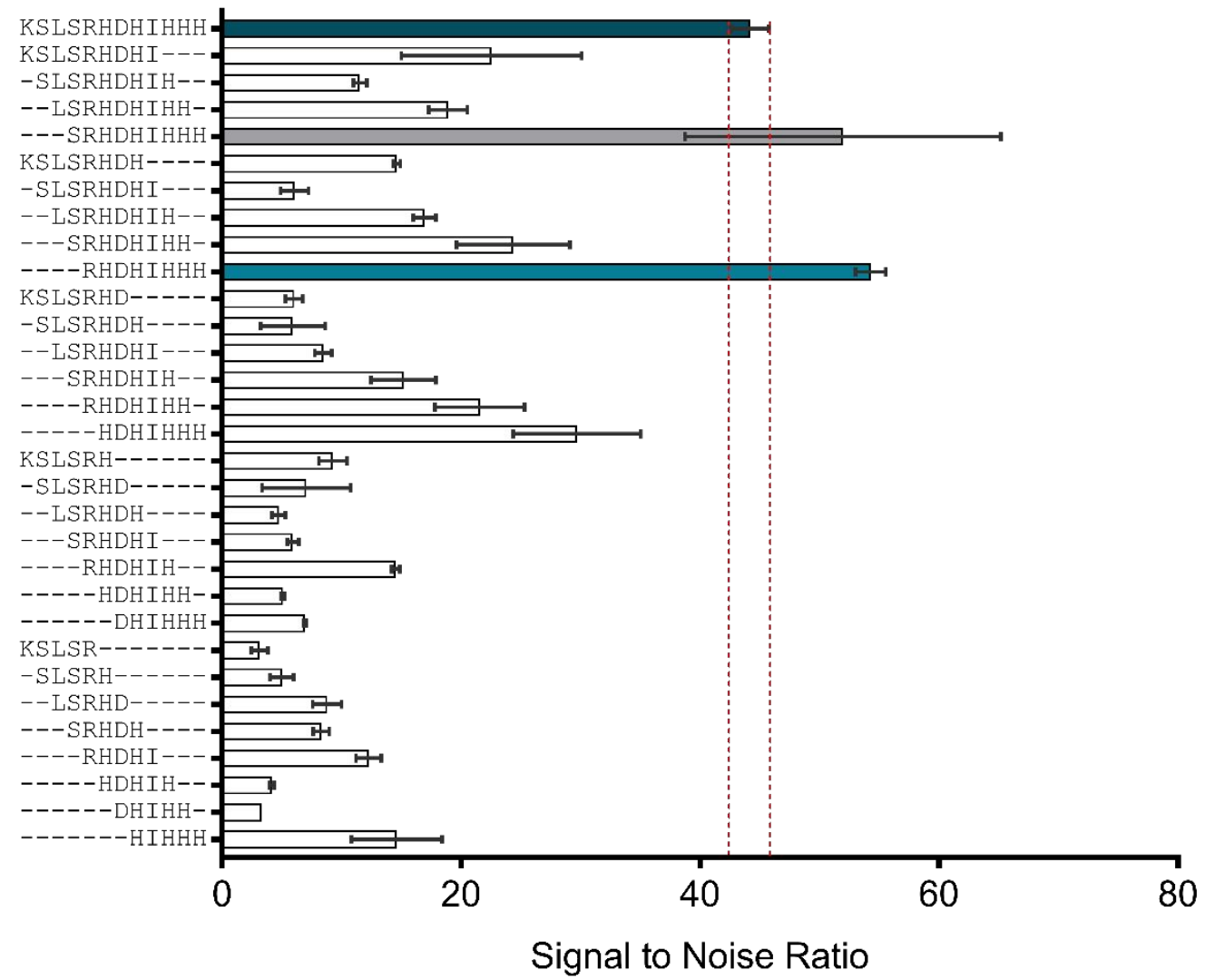

Figure S 17 - Truncation data for LS3, screened against $\mathrm{Pt}^{2+}$.

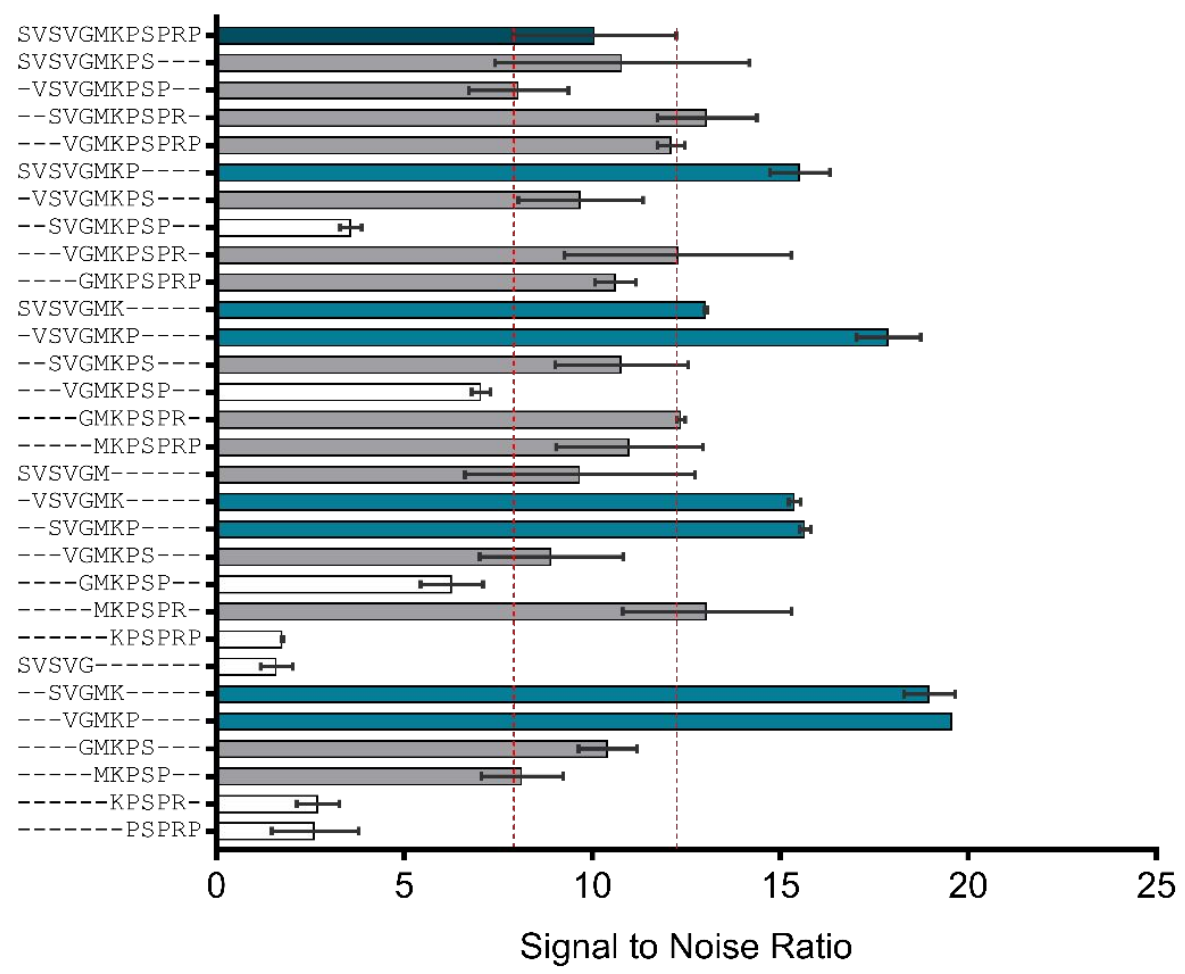

Figure S 18 - Truncation data for LS4, screened against $\mathrm{Pt}^{2+}$. 


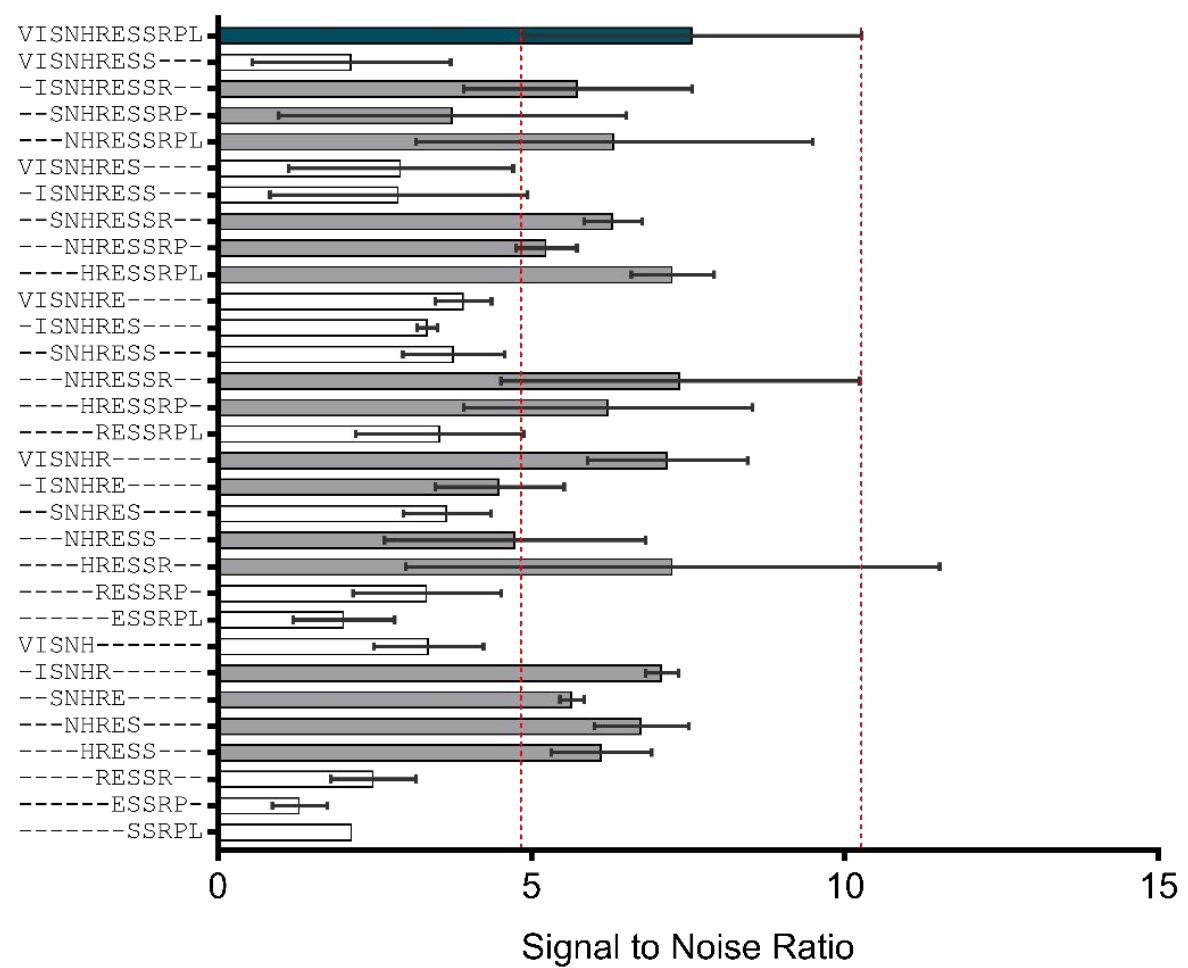

Figure S 19 - Truncation data for LS5, screened against $\mathrm{Pt}^{2+}$.

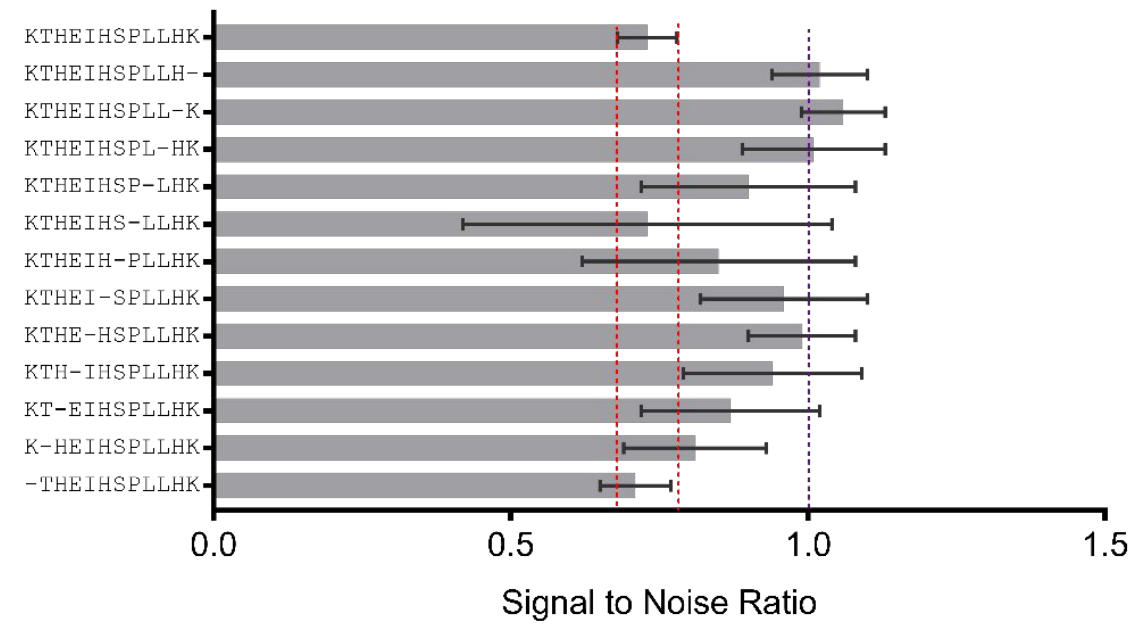

Figure S 20 - Alanine scanning data for LS1, collected from screening against a synthesis reaction. Dotted purple line represents background noise. 


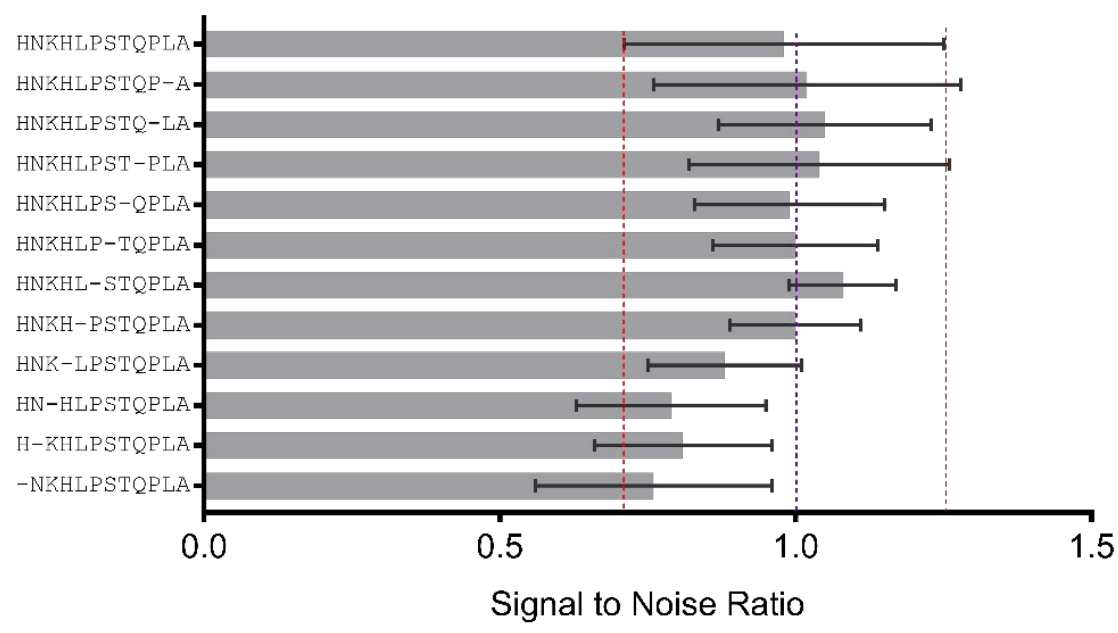

Figure S 21 - Alanine scanning data for LS2, collected from screening against a synthesis reaction. Dotted purple line represents background noise.

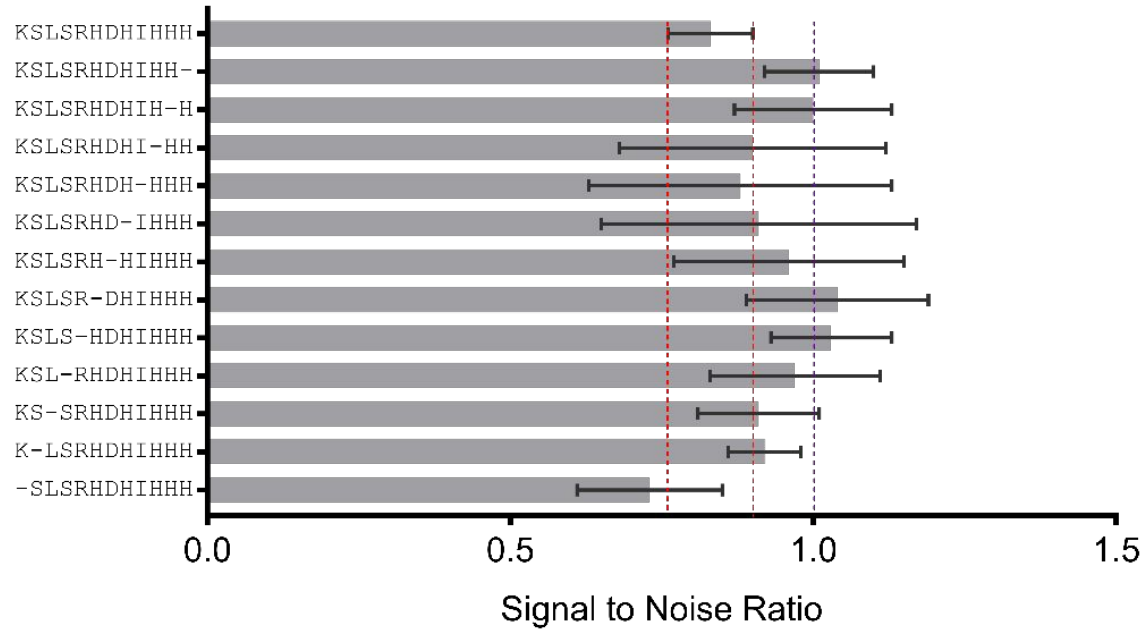

Figure S 22 - Alanine scanning data for LS3, collected from screening against a synthesis reaction. Dotted purple line represents background noise.

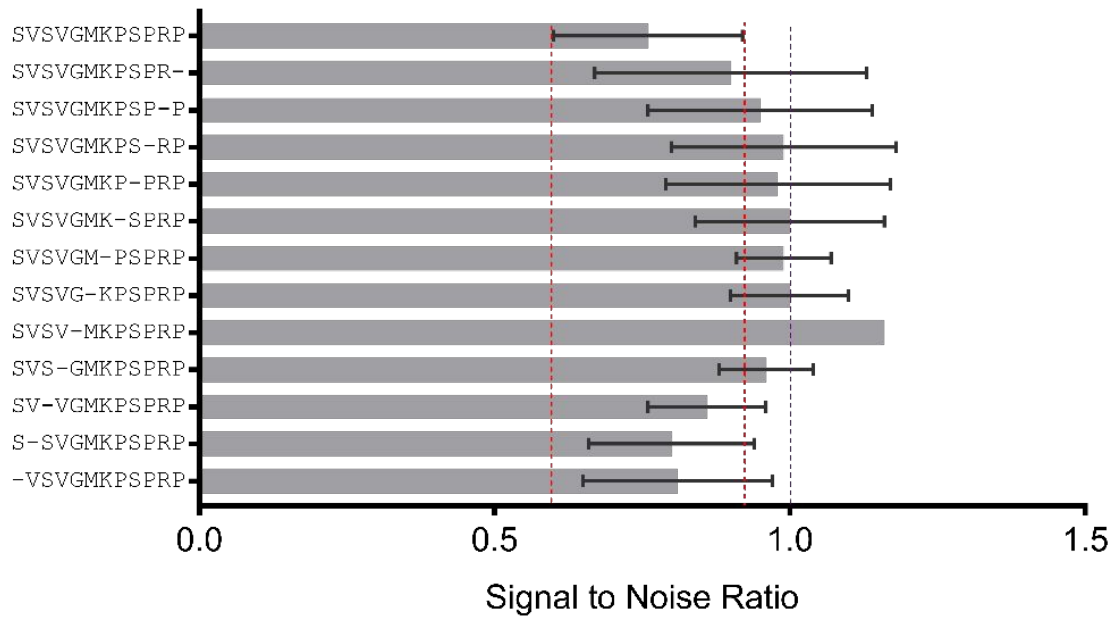

Figure S 23 - Alanine scanning data for LS4, collected from screening against a synthesis reaction. Dotted purple line represents background noise. 


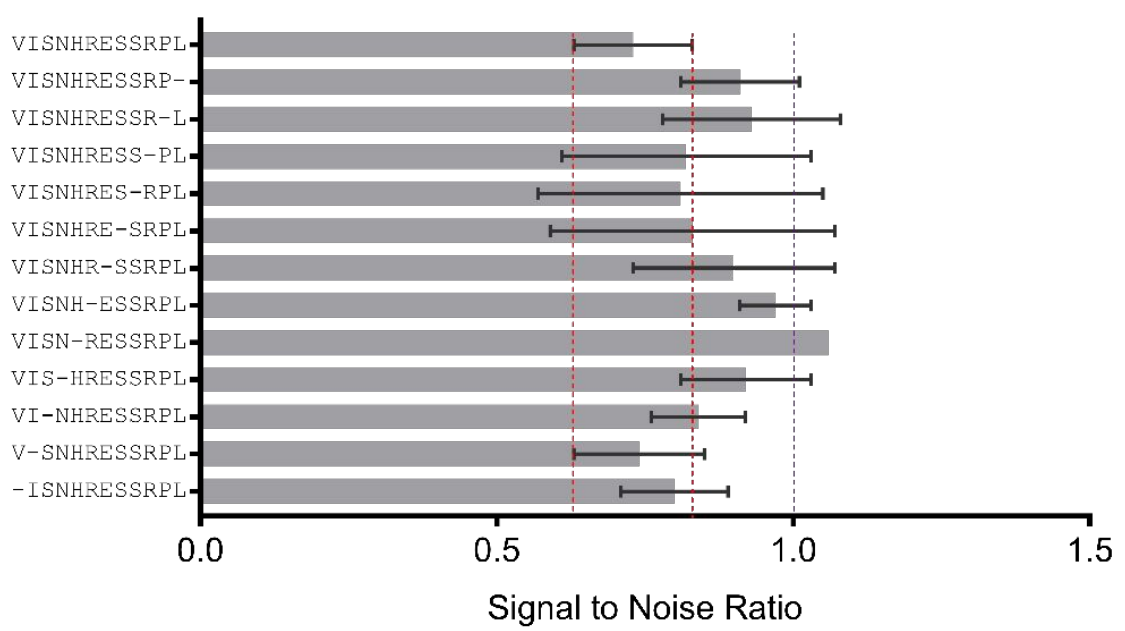

Figure S 24 - Alanine scanning data for LS5, collected from screening against a synthesis reaction. Dotted purple line represents background noise.

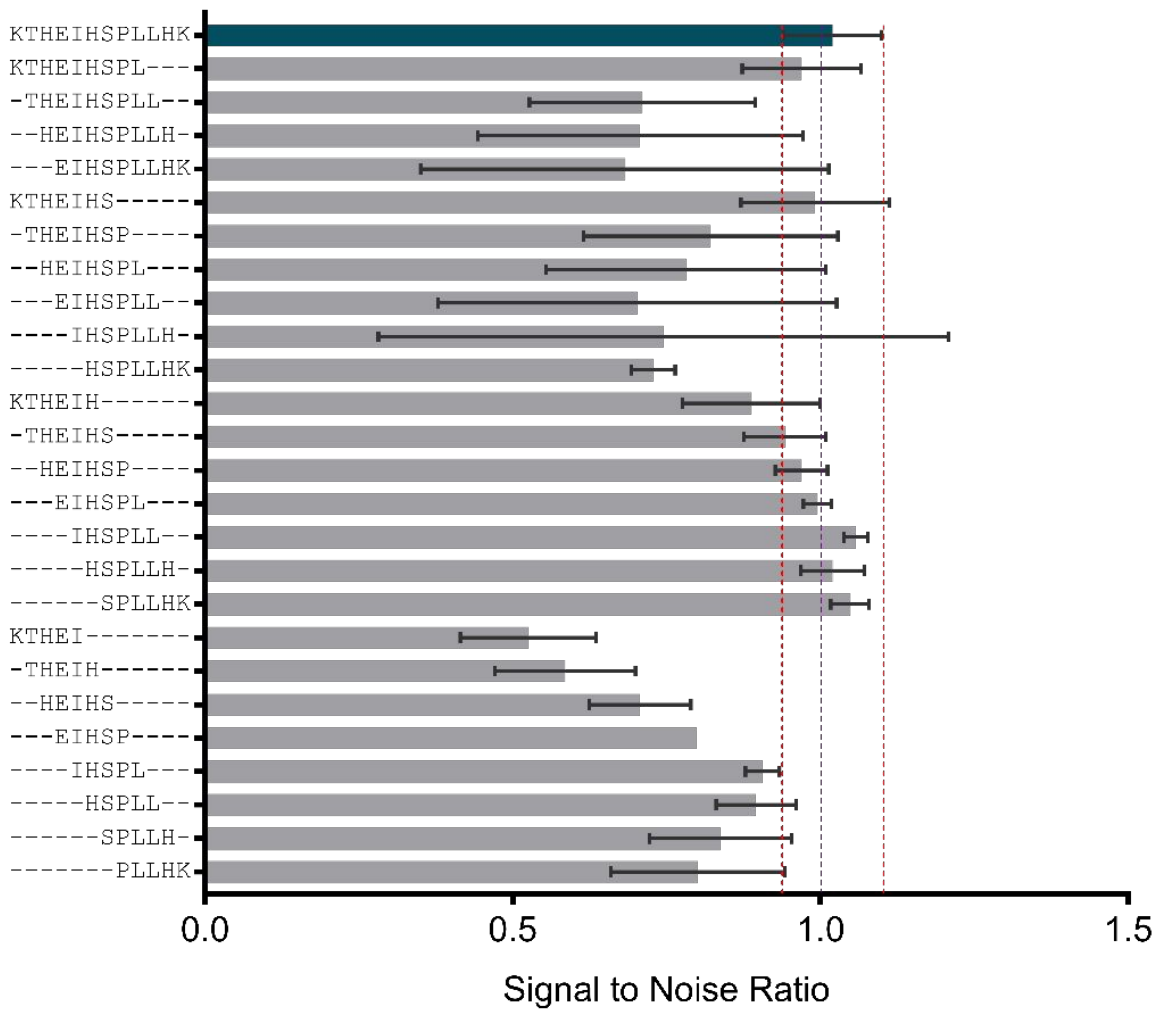

Figure S 25 - Truncation data for LS1, collected from screening against a synthesis reaction. Dotted purple line represents background noise. 


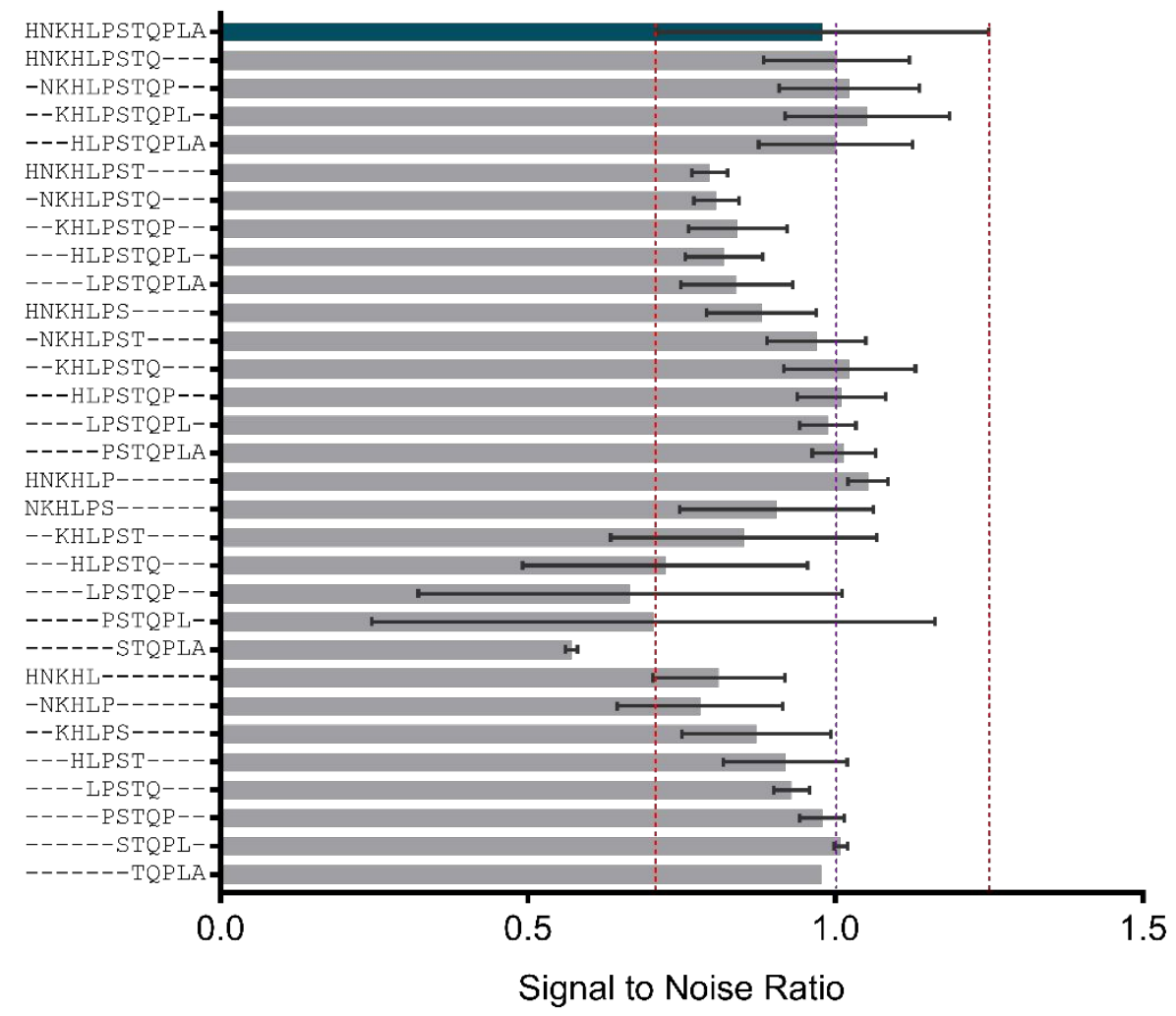

Figure S 26 - Truncation data for LS2, collected from screening against a synthesis reaction. Dotted purple line represents background noise.

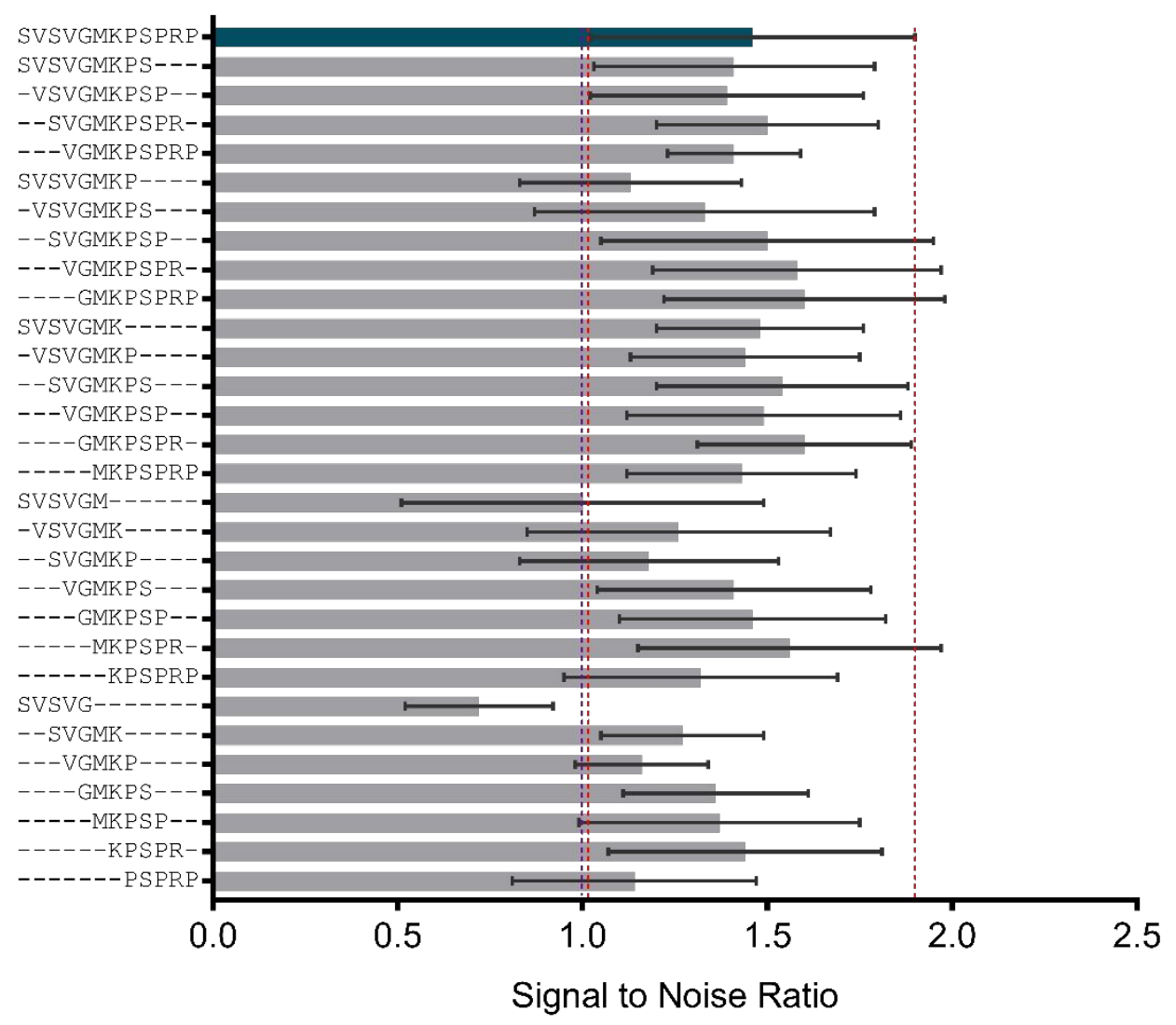

Figure S 27 - Truncation data for LS4, collected from screening against a synthesis reaction. Dotted purple line represents background noise. 


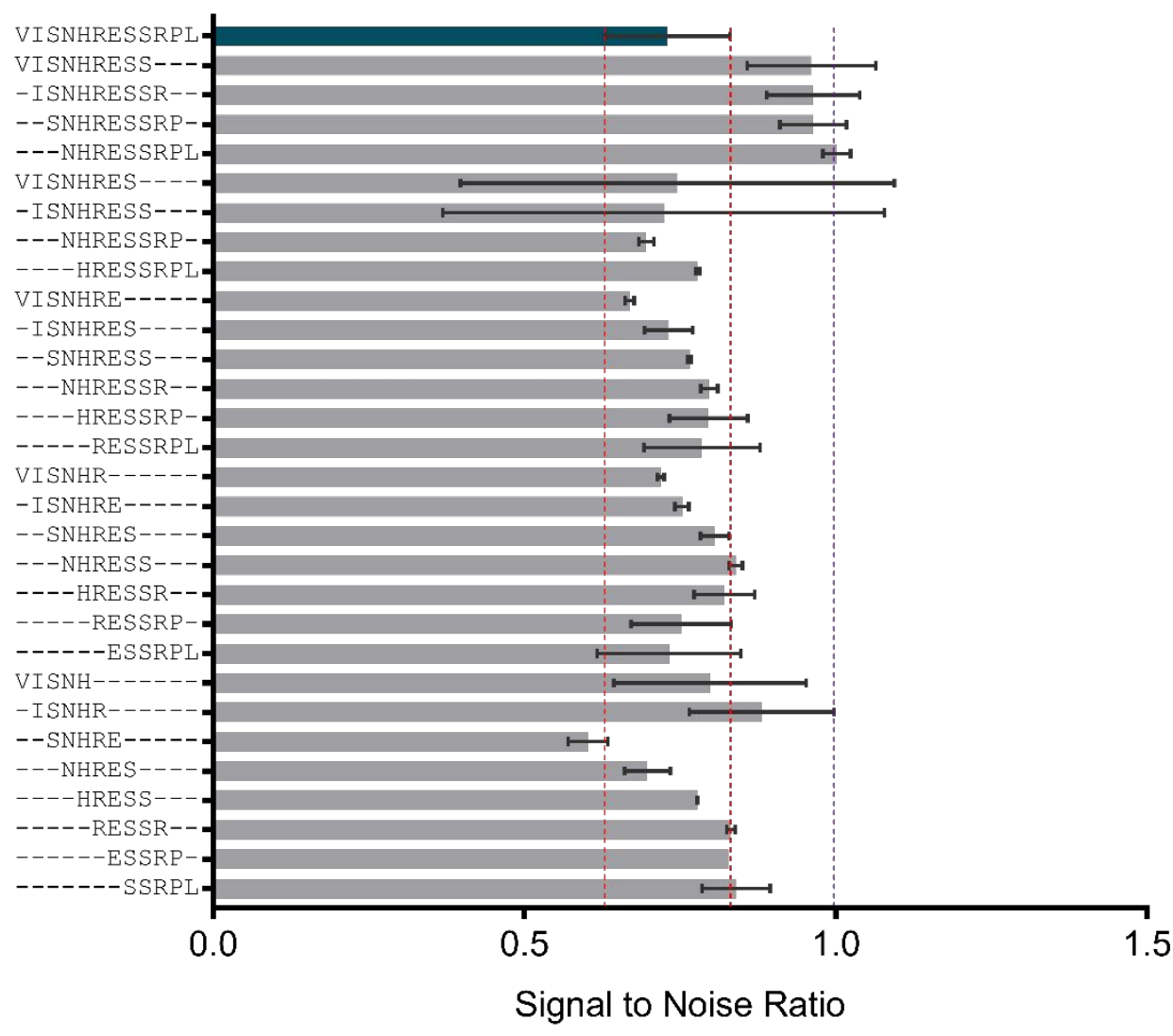

Figure S 28 - Truncation data for LS5, collected from screening against a synthesis reaction. Dotted purple line represents background noise. 


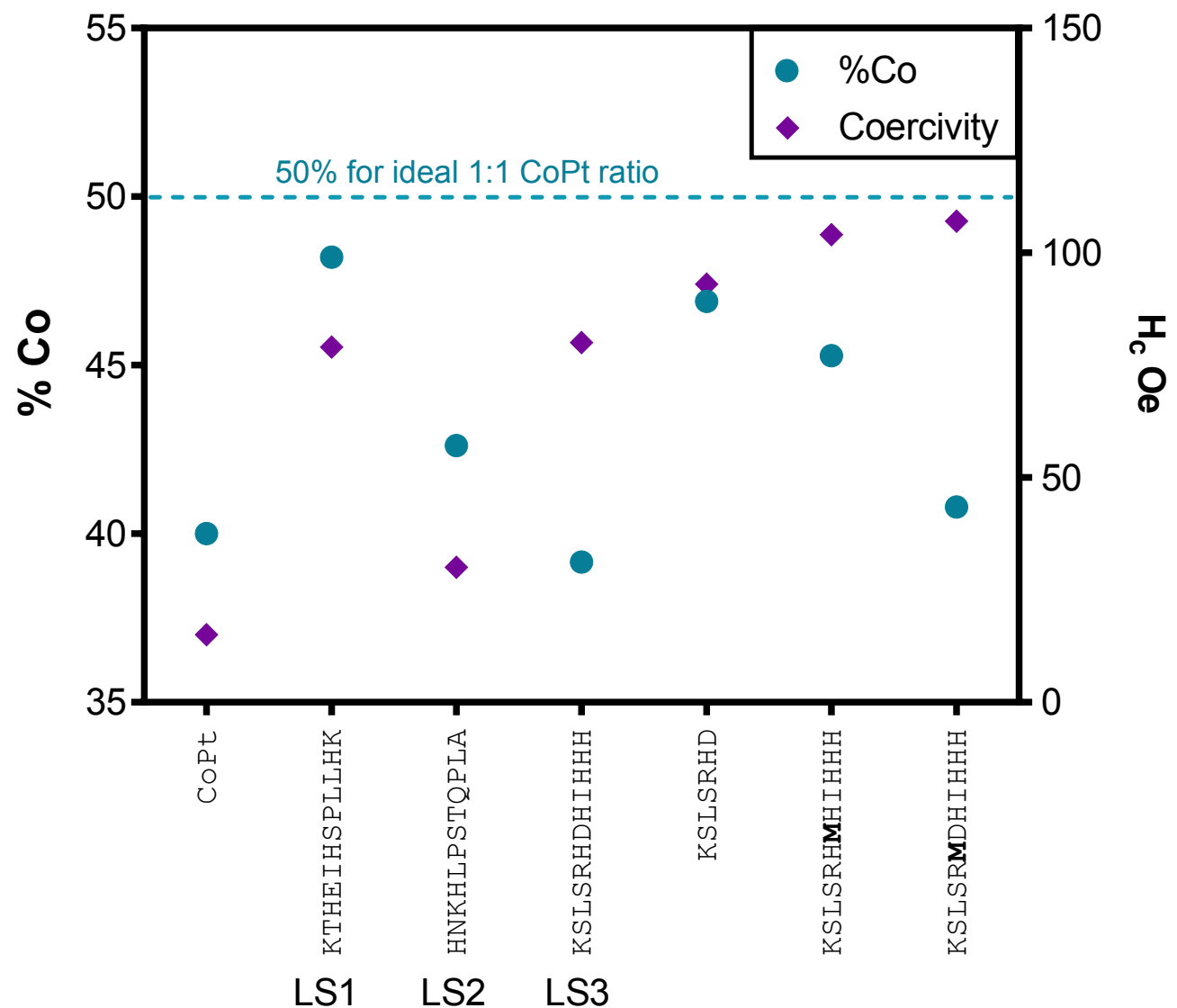

Figure S 29 - Graph to show the ratio of cobalt to platinum (left y-axis shows \% of cobalt (teal circles)) compared to magnetic coercivity (right y-axis (purple diamonds) data duplicated from figure 10 in manuscript). 